\title{
BMJ Open Which older Brazilians will accept a COVID-19 vaccine? Cross-sectional evidence from the Brazilian Longitudinal Study of Aging (ELSI- Brazil)
}

\author{
James Macinko (1) , ${ }^{1,2}$ Brayan V Seixas, ${ }^{1}$ Juliana Vaz de Melo Mambrini, ${ }^{3}$ \\ M Fernanda Lima-Costa (iD) ${ }^{3,4}$
}

To cite: Macinko J, Seixas BV, Mambrini JVdM, et al. Which older Brazilians will accept a COVID-19 vaccine? Crosssectional evidence from the Brazilian Longitudinal Study of Aging (ELSI-Brazil). BMJ Open 2021;11:e049928. doi:10.1136/ bmjopen-2021-049928

- Prepublication history and additional supplemental material for this paper are available online. To view these files, please visit the journal online (http://dx.doi.org/10.1136/ bmjopen-2021-049928)

Received 06 February 2021 Accepted 20 October 202
Check for updates

(C) Author(s) (or their employer(s)) 2021. Re-use permitted under CC BY-NC. No commercial re-use. See rights and permissions. Published by BMJ.

For numbered affiliations see end of article.

Correspondence to Dr James Macinko; jmacinko@ucla.edu

\section{ABSTRACT}

Objectives Vaccine hesitancy may represent a barrier to effective COVID-19 immunisation campaigns. This study assesses individual, disease-specific and contextual factors associated with COVID-19 vaccine acceptance among a nationally representative sample of older Brazilian adults.

Design Cross-sectional analysis of data from household interviews and a supplementary telephone survey.

Setting Brazil and its five geographic regions.

Participants Data are derived from 6584 individuals aged 50 years and over who participated in the second wave of the Brazilian Longitudinal Study of Aging.

Primary and secondary outcome measures Surveyweighted multinomial logistic regression assesses factors associated with intending, not intending or being uncertain about one's intention to vaccinate against COVID-19.

Findings Seventy-one per cent of study participants intend to receive a COVID-19 vaccine once available, while $17 \%$ (representative of nearly 9 million people) have no intention to vaccinate, and $12 \%$ are still undecided. Besides age, demographic and health-related factors related to COVID-19 severity and complications were not associated with intention to vaccinate. Those who most trusted social media or friends and family for COVID-19 information and those who did not trust any information source were $68 \%$ and $78 \%$ more likely to refuse vaccination, respectively, as compared with those who trusted official information sources. People who inconsistently used face masks when outside were 3.4 times more likely than consistent face mask users to intend to refuse vaccination. Higher municipal COVID-19 fatality rates were negatively associated with vaccine refusal.

Conclusions Most national COVID-19 immunisation strategies identify older individuals as among those prioritised for early vaccination, given their increased risk of more severe symptoms and complications of the disease. Because individual, disease-specific, and contextual factors were associated with vaccine acceptance, there is a clear need for multilevel and multichannel information and outreach campaigns to

\section{STRENGTHS AND LIMITATIONS OF THIS STUDY}

$\Rightarrow$ To our knowledge, no previous studies have quantified the level of COVID-19 vaccine hesitancy among older Brazilian adults after the results of most COVID-19 vaccine trials were made public, nor systematically tested the relationship between vaccine intention and individual, disease-specific and contextual factors related to the full range of COVID-19 vaccine intentions.

$\Rightarrow$ The study's advantages include its large sample size, representative at both national and regional levels and its inclusion in a well-defined populationbased cohort, allowing for examination of an array of factors obtained from in-person interviews as well as via telephone survey.

$\Rightarrow$ The limitations of the study include those related to the self-reported nature of the data, potential recall bias, respondents not answering calls or refusing to provide information via this means and incorrect or non-existent phone numbers.

$\Rightarrow$ A final limitation is that positive vaccine intentions may not automatically translate into receipt of a vaccine as such decisions are complex and may be driven by factors that change over time.

increase COVID-19 vaccine acceptance among vulnerable older populations.

\section{INTRODUCTION}

The community transmission of the SARS-CoV-2 was officially recognised in Brazil on 20 March $2020^{1}$; since then, the number of new cases and deaths have grown considerably. As of 5 July 2021, the total number of new infections reached 18.8 million and there had been 524417 deaths, making Brazil the second most affected country in terms of mortality, after the USA. ${ }^{2}$

Globally, the syndrome caused by SARS-CoV-2 (COVID-19) affects older adults and those with pre-existing chronic conditions more severely. ${ }^{3}$ 
Brazil has one of the world's largest older populations: a quarter of the population is aged 50 years or more and 30 million Brazilians are aged 60 and over. ${ }^{4}$ By May-June 2020, $2.4 \%$ of Brazilians aged 50 years and older reported being told by their doctor they had COVID-19. Demographic factors (age 50-60 years), socioeconomic factors (lower household income), health-related factors (obesity, three or more chronic conditions) and geography (living in the North region of the country) were all positively associated with reporting a COVID-19 diagnosis. ${ }^{5}$

For COVID-19 vaccines to turn the course of the pandemic, governments must engage in an unprecedented campaign to procure sufficient quantities of vaccine, develop distribution and logistics systems and ensure equitable access to them-a challenge that is even more acute in middle and low-income countries. ${ }^{6}$ In this context, the public's acceptance of the vaccine is crucial. Mistrust in local authorities, misinformation, confusion and fear may all affect the level of acceptance of a COVID-19 vaccine. In many countries, increasing vaccine hesitancy combined with rapidly propagated misinformation present substantial obstacles to achieving sufficiently high levels of immunisation to adequately slow viral transmission. For example, an analysis from 19 countries showed that in June/July 2020 about 72\% would accept a COVID-19 vaccine, ranging from a low of $55 \%$ in Russia to $85 \%$ in Brazil and $89 \%$ in China. ${ }^{7}$ It is important to note, however, that these figures refer to the entire adult population and do not focus on older populations that have been prioritised for early vaccine delivery.

Larson $e t a l^{8}$ suggest there are three main domains associated with vaccine hesitancy-defined as a continuum between vaccine acceptance and refusal. These include individual and group influences, such as demographic and socioeconomic factors that affect people's perceptions of vaccines and the behaviour of their peers; vaccination-specific issues related to the disease, the vaccine and the immunisation process; and contextual influences stemming from macrolevel factors such as the social, cultural, political, health system and other environmental factors. While a recent global survey $^{9}$ found that $80 \%$ of Brazilians express the view that vaccines are safe, there has been increased evidence of vaccine hesitancy reported in the country for the past few years, resulting in declining rates for some immunisations among children (eg, Bacille Calmette-Guérin or BCG and rotavirus) and adults (eg, hepatitis B and influenza). ${ }^{1011}$

The Brazilian Longitudinal Study of Aging (ELSIBrazil) ${ }^{12}$ has surveyed cohort participants on COVID19-related topics through its ELSI-COVID initiative. ${ }^{13}$ In November/December 2020, cohort members were given a supplementary telephone-based survey on acceptance of vaccines against COVID-19. In this study, we present findings from this first nationally representative survey on factors affecting the COVID-19 vaccine intentions among older Brazilian adults.
METHODS

\section{Data}

ELSI-Brazil is a nationally representative population-based cohort study composed of community-dwelling Brazilians aged 50 years and older. The study uses probability sampling clustered in strata that combine municipalities, census tracts and households. The final sample included 70 municipalities in all five major geographic regions of the country. The baseline survey included 9412 participants and was conducted from 2015 to 2016. The second ELSI-Brazil wave started in August 2019 but was interrupted on 17 March due to the SARS-CoV-2 pandemic. Until its interruption, 9177 wave 2 participants had been interviewed in-person and their physical measurements were taken. Public use ELSI-Brazil wave 2 data will be made publicly available online. ${ }^{12}$

All individuals who participated in the second wave of ELSIBrazil were eligible for the subsequent ELSI-COVID-19 telephone interviews, carried out between May and November 2020. A description of the ELSI-COVID-19 telephone survey initiative and its methods are available elsewhere. ${ }^{13}$

\section{Measures}

Measures come from the face-to-face interviews from the second wave of ELSI-Brazil (pre-COVID-19), the subsequent telephone surveys and from administrative data sources providing information about the respondent's municipality of residence.

Variables derived from the in-person household interviews (conducted pre-COVID-19) included sex, age, conjugal status (married/partnered vs others), years of schooling (up to 4, 5-8, 9 and over), self-reported skin colour (white vs others), urban versus rural residence, geographic region (North, Northeast, Southeast, South and Mid-West), having a private health plan, and affiliation with Brazil's community-based primary healthcare programme, the Family Health Strategy (FHS). Healthrelated factors included current smoking, self-rated health (fair/poor vs good/very good/excellent), previous diagnosis of a list of chronic conditions (asthma, congestive heart failure, myocardial infarction, angina pectoris, chronic obstructive pulmonary disease, hypertension, cancer), any limitations in basic activities of daily living, receipt of a influenza shot in the past year and obesity calculated from a measured body mass index of $\geq 30 \mathrm{~kg}$ / $\mathrm{m}^{2}$.

Variables from the post-COVID-19 telephone survey include the main outcome variable: acceptance of a COVID-19 vaccine based on the question, "When the vaccine for COVID-19 is released, do you intend to get it?'. Responses were categorised as 'yes', 'no' and 'don't know/unsure'. Explanatory variables from the telephone interview included the respondent's most trusted source of information about the pandemic, 'given the amount of information about COVID-19, what is the source of information about the disease that you trust the most?' which was coded into the following categories: (1) official sources (Ministry of Health, mayor, governor), (2) traditional media (television, newspaper, journalists), (3) 
social media (WhatsApp, Twitter, Facebook, internet), friends/family, or other source(s) or (4) trusts no listed sources. The interview asked whether the participant had ever received a diagnosis of COVID-19, if any family members or neighbours had been diagnosed with COVID-19, and the respondent's use of face masks when outside the home in the past week ('always' was defined as consistent use vs 'less than always' defined as inconsistent use).

Municipal-level variables obtained from the Brazilian Ministry of Health's online portal included: hospital beds per capita, population size (in 1000 s), FHS municipal population coverage (categorised as $<40 \%$ vs higher). Cumulative COVID-19 cases (per 1000) and deaths (per 100000 ) as of 23 November 2020 were obtained online. ${ }^{14}$ Municipal-level COVID-19 fatality rates were calculated as deaths $/$ cases $\times 100$.

\section{Statistical analysis}

Descriptive results are reported as percentages or means and their respective 95\% CIs. A design-corrected F-test (similar to a $\chi^{2}$ test, but adjusted for survey-weighted data) and survey-weighted linear regression were used to examine the statistical significance of differences between proportions and means, respectively. These bivariate analyses were used to describe the relationship between a range of explanatory variables identified in the literature and the outcome (the three categories of vaccine intention) to determine potential candidates for multivariable analysis. Multinomial logistic regression was used for multivariable analyses, with the most prevalent outcome category (will accept a vaccine) set as the reference. The final regression model was built on the descriptive analysis and previous literature. Predicted probabilities for the main, statistically significant explanatory variables (inconsistent face mask use, municipal COVID-19 case and fatality rates and most trusted source of health information) were calculated from the final model and displayed graphically. Analyses controlled for the complex sample design and survey weights specifically designed for the telephone survey. Sensitivity tests that included adjusting for municipal-level clustering of standard errors did not substantially modify any main result. Analyses were performed using Stata V.16. We used the Strengthening the Reporting of Observational Studies in Epidemiology cross-sectional checklist when writing our report.

\section{Patient and public involvement}

Neither study participants nor the public were involved in the study design, conduct, data analysis, reporting, interpretation or planning of dissemination of our research.

\section{RESULTS}

Table 1 presents participant characteristics by vaccination intention. Of the 9177 eligible ELSI-Brazil participants, 6681 $(72.8 \%)$ participated in the telephone interviews, conducted in mid-November, 2020. Of these, 97 (1.4\%) had missing values for one or more measures and were dropped. Seventy-one per cent of participants expressed the intention to receive a COVID-19 vaccine once available, $16.9 \%$ expressed no intention to vaccinate and $12.2 \%$ were uncertain about whether they would vaccinate. The mean age was 63.2 years and was slightly lower (62.9) among those who intended to accept a vaccine. None of the sociodemographic factors (sex, educational attainment, household income, conjugal status, white skin colour), health conditions, healthcare coverage categories differed across vaccination intention categories. Those who intend to vaccinate had the highest rates of face mask use and were slightly more concentrated in rural areas and in municipalities with the highest municipal hospital beds per capita. One-third of participants know someone who had COVID-19, but this proportion did not vary significantly by vaccine intention. The most trusted source of information on COVID-19 for all participants was government/official sources $(43.1 \%)$ followed by traditional media $(31.4 \%)$, social media or family/friends (14.4\%) and no trusted source $(11.1 \%)$. The latter two categories were lowest among those who intended to receive a vaccine $(\mathrm{p}<0.001)$. Statistically significant differences across vaccine intention categories were found within the North, South and Southeast regions.

Figure 1 shows the relative frequency of participants' most trusted source of COVID-19 information, by region and vaccine intention. Across all regions and vaccine intentions, official sources or traditional media was the most common source of trusted health information, ranging from $94 \%$ among vaccine accepters in the North to $50 \%$ among those with uncertain vaccine intentions in the South. Having social media, friends or family as the most trusted source of health information or having no trusted sources was consistently more common among those who intend to refuse a vaccine, ranging from $44 \%$ in the Northeast to 23\% in the South. Vaccine uncertainty generally followed the same pattern as vaccine acceptance within each region.

Table 2 shows relative risk ratios from the multinomial logistic regression of intention to vaccinate against COVID19. Positive intention to vaccinate is the reference category for both outcomes (vaccine refusal and undecided). In comparison to those aged 50-59, individuals aged 60-74 are 1.59 times more likely and those aged 75 and over are 2.46 times more likely to express no intention to vaccinate. Inconsistent face mask users (compared with consistent users) are 3.41 times more likely to refuse vaccination. Individuals who most trust social media or friends and family or who have no trusted media sources are approximately $70 \%$ more likely than those who rely on official sources to express no intention to vaccinate against COVID-19. Regional variations are also statistically significant predictors of vaccine refusal, with the lowest rates (as compared with the Southeast) observed in the North and South. Different measures of COVID-19 severity were negatively associated with the two outcomes: vaccine refusal falls as municipal fatality rates rise, and vaccine uncertainty likewise falls as cumulative municipal cases per 1000 population rise. No statistically significant associations were observed for gender, educational attainment, chronic 
Table 1 Intention to vaccinate against COVID-19 among participants in the telephone survey of the Brazilian Longitudinal Study of Aging (ELSI-COVID-19 initiative), by socio-demographic, health status, COVID-19 risk factors, and municipal-level characteristics, 16-29 November 2020

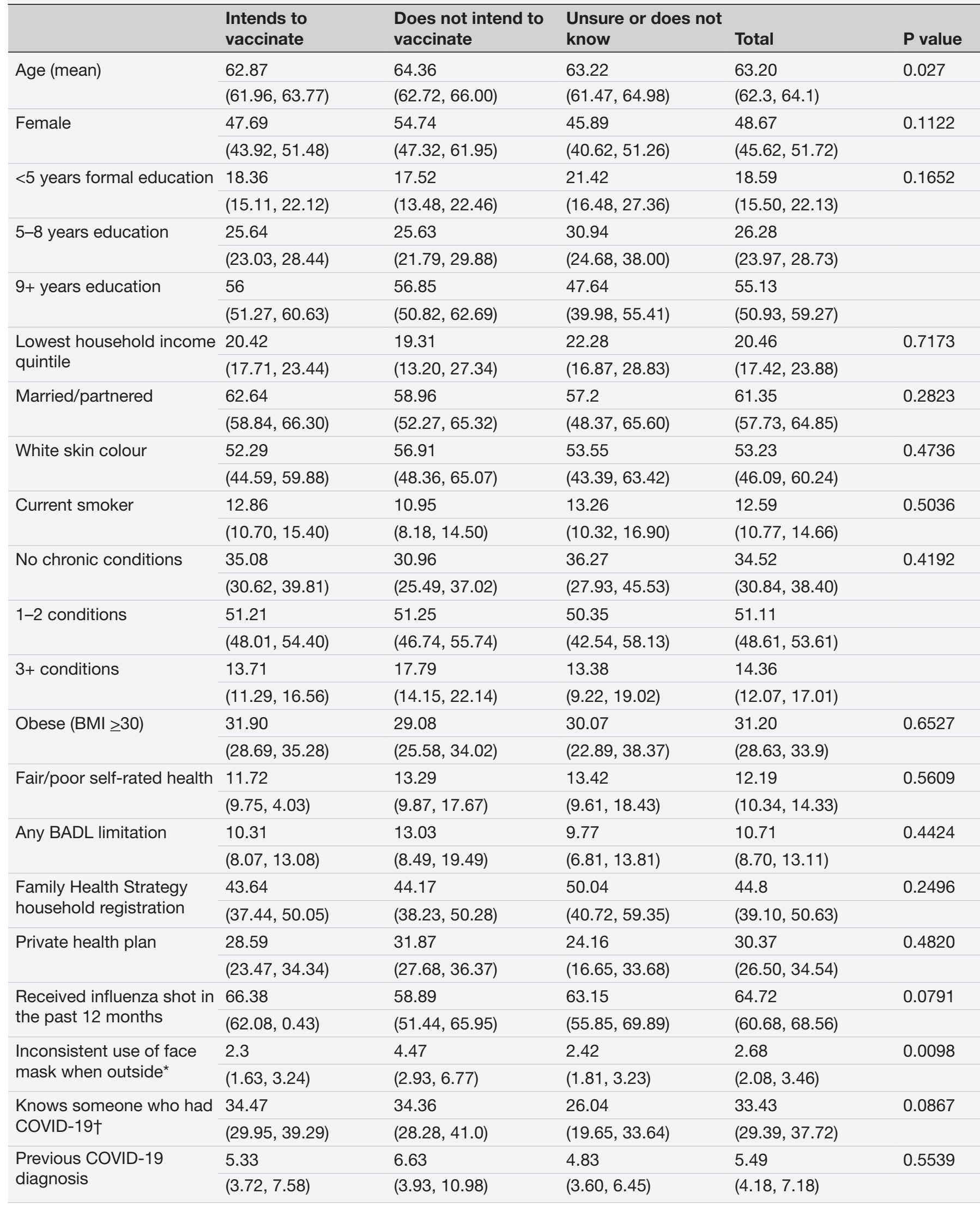


Table 1 Continued

\begin{tabular}{|c|c|c|c|c|c|}
\hline & $\begin{array}{l}\text { Intends to } \\
\text { vaccinate }\end{array}$ & $\begin{array}{l}\text { Does not intend to } \\
\text { vaccinate }\end{array}$ & $\begin{array}{l}\text { Unsure or does not } \\
\text { know }\end{array}$ & Total & P value \\
\hline $\begin{array}{l}\text { Official } \ddagger \text { sources for } \\
\text { COVID-19 information }\end{array}$ & 44.42 & 36.59 & 44.46 & 43.11 & $<0.0001$ \\
\hline \multirow{2}{*}{$\begin{array}{l}\text { Traditional media§ is the } \\
\text { most trusted information } \\
\text { source }\end{array}$} & 33.83 & 25.38 & 25.34 & 31.41 & \\
\hline & $(30.49,37.33)$ & $(20.81,30.57)$ & $(20.42,30.98)$ & $(28.71,34.23)$ & \\
\hline $\begin{array}{l}\text { Social media/family/ } \\
\text { others as most trusted } \\
\text { information }\end{array}$ & $(10.72,14.87)$ & $(16.96,25.69)$ & $(10.71,22.06)$ & $(12.45,16.59)$ & \\
\hline \multirow{2}{*}{$\begin{array}{l}\text { No trusted source of } \\
\text { COVID-19 information }\end{array}$} & 9.1 & 17.03 & 14.64 & 11.09 & \\
\hline & $(7.61,10.84)$ & $(13.69,21.00)$ & $(10.84,19.49)$ & $(9.44,12.98)$ & \\
\hline Rural residence (vs urban) & 15.26 & 10.71 & 14.03 & 14.34 & 0.0295 \\
\hline \multirow[t]{2}{*}{ Northeast region } & 75.85 & 14.6 & 9.55 & 26.32 & 0.1475 \\
\hline & $(69.08,81.53)$ & $(9.95,20.92)$ & $(7.33,12.36)$ & $(18.13,36.57)$ & \\
\hline \multirow[t]{2}{*}{ Southeast region } & 64.23 & 23.79 & 11.98 & 39.28 & 0.0000 \\
\hline & $(58.64,69.46)$ & $(19.32,28.92)$ & $(9.73,14.67)$ & $(28.30,52.72)$ & \\
\hline \multirow[t]{2}{*}{ South region } & 75.14 & 10.31 & 14.55 & 16.73 & 0.0002 \\
\hline & $(71.9,78.11)$ & $(8.22,12.86)$ & $(12.31,17.11)$ & $(8.15,31.26)$ & \\
\hline \multirow[t]{2}{*}{ Mid-west region } & 73.5 & 14.24 & 12.26 & 9.91 & 0.7456 \\
\hline & $(63.03,81.86)$ & $(9.75,20.32)$ & $(5.77,24.19)$ & $(5.09,18.41)$ & \\
\hline \multirow{2}{*}{$\begin{array}{l}\text { Municipal COVID-19 } \\
\text { cases per } 1000\end{array}$} & 22.46 & 23.01 & 21.65 & 22.47 & 0.121 \\
\hline & $(20.12,24.80)$ & $(20.85,25.18)$ & $(18.90,24.40)$ & $(20.24,24.71)$ & \\
\hline \multirow{2}{*}{$\begin{array}{l}\text { Municipal COVID-19 case } \\
\text { fatality rate }(\%)^{\star *}\end{array}$} & 3.72 & 3.44 & 3.62 & 3.66 & 0.449 \\
\hline & $(3.35,4.13)$ & $(2.96,3.93)$ & $(2.89,4.34)$ & $(3.25,4.07)$ & \\
\hline $\begin{array}{l}\text { Weighted } \\
\text { proportion }\end{array}$ & 70.82 & 16.98 & 12.20 & 100 & \\
\hline $\begin{array}{l}\mathrm{N} \\
\text { (weighted) }\end{array}$ & 37324954 & 8950783 & 6429516 & 52705253 & \\
\hline $\begin{array}{l}\mathrm{N} \\
\text { (unweighted) }\end{array}$ & 4524 & 1186 & 874 & 6584 & \\
\hline
\end{tabular}

All numbers are weighted percentages except where specified; $95 \%$ Cls are in brackets; $p$ values come from design-corrected F-test for difference between groups.

*Those who left the home in the past 7 days and reported less frequent face mask use than 'always'.

†Knows either a household member or neighbour who was diagnosed with COVID-19.

¥Ministry of Health and political leaders, governors/authorities.

$\S$ Traditional media are radio, television, newspapers or journalists.

१Regional analyses present weighted proportions of individuals in each vaccine intention category, within that region. The numbers in the total column represent the relative population size of each region. The $p$ values are from a design-corrected F-test of the hypothesis that within-region proportions are equivalent across vaccine intention categories.

${ }^{* *}$ Total cumulative municipal deaths/total cumulative municipal cases ${ }^{*} 100$.

BADL, basic activities of daily living; BMI, body mass index; FHS, Family Health Strategy. 


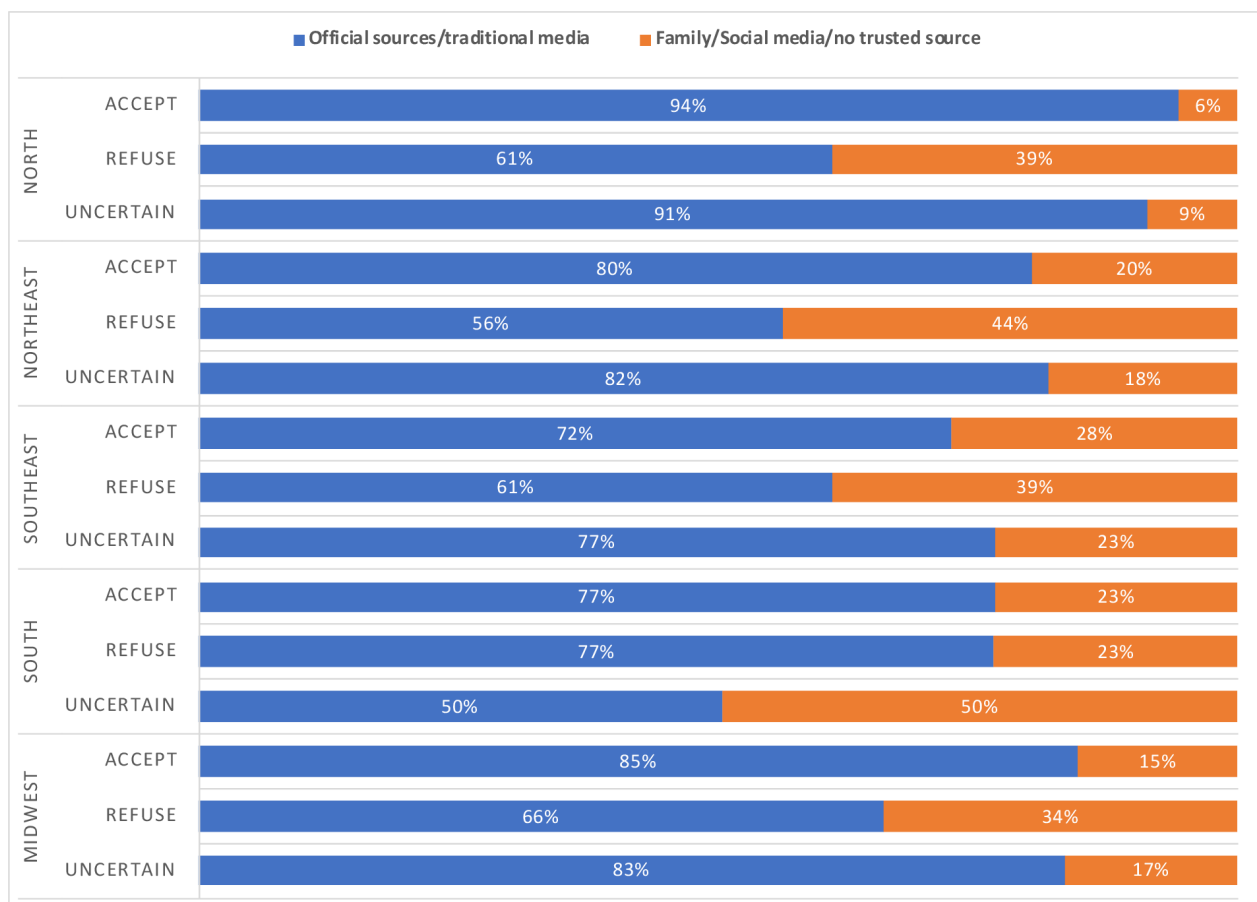

Figure 1 Proportion of most trusted source of information on COVID-19, by intention to receive COVID-19 vaccine and region, among participants in the telephone survey of the Brazilian Longitudinal Study of Aging (ELSI-COVID-19 initiative), 16-29 November 2020. Numbers are weighted proportions of most trusted information source by vaccine intention category within each region. Due to rounding, totals may not always add to 100 .

conditions, rural/urban residence or municipal population size in fully adjusted analyses. There was little evidence of multicollinearity in the final model (average variance inflation factor $=1.20)$.

Figure 2 shows predicted probabilities of intention not to vaccinate against COVID-19 stratified by the main explanatory variables found to be statistically significant predictors of vaccine refusal. Those who most trust social media/friends/ family and those who trust no information sources are about two times as likely to report intending to refuse a COVID-19 vaccine than those who most trust official sources or traditional media outlets. For all trusted information sources, the probability of vaccine refusal is lowest where municipal COVID-19 fatality rates are highest. For all trusted information sources, inconsistent (as compared with consistent) face mask use is associated with about two times the probability of vaccine refusal.

Figure 3 shows predicted probabilities of the main factors associated with being uncertain about receiving a COVID-19 vaccine as presented in table 2 . Uncertainty slightly decreases for all participants as the rate of municipal COVID-19 cases increases. Among those with consistent face mask use, those who most trust traditional media have the lowest predicted rates of vaccine uncertainty, while those who trust no information sources have the highest predicted probability of vaccine uncertainty. Among those with inconsistent face mask use, the lowest rates of vaccine uncertainty are observed among those who most trust social media, while the highest predicted rates are observed among those who most trust official sources and among those who trust no information sources.

\section{DISCUSSION}

Our results show that $71 \%$ of participants intended to vaccinate when COVID-19 vaccines become available, while $17 \%$ had no intention to vaccinate and $12 \%$ were still uncertain. Given the nationally representative nature of the survey, this translates to about 8.9 million Brazilians aged 50 and over who do not intend to vaccinate and 6.4 million who are unsure. These results have implications for Brazil's National COVID-19 Vaccination Plan, ${ }^{15}$ which identifies four priority groups, totalling 50 million people. In addition to frontline health workers, the first priority group is made up of people aged 75 and over and the second group consists of people aged 60 and over. Together, the number of refusals and unsure older adults identified in this study represent about $17 \%$ of the population prioritised for early vaccination.

Most demographic factors, except age, were not associated with vaccine refusal or uncertainty. Among those aged $60-74$ and 75 years or older, respectively, $18 \%$ and $22 \%$ do not intend to be vaccinated, while $12 \%$ and $14 \%$ are undecided about vaccination. This finding contrasts with worldwide patterns identified in a systematic review that shows age is positively associated with being more receptive to a COVID-19 vaccine. ${ }^{16}$ One explanation for this discrepancy may be that other studies have surveyed the entire adult population, whereas this study focused only on older adults, using age $50-59$ as the reference category.

Heart conditions, chronic obstructive pulmonary diseases, diabetes mellitus and obesity are thought to be associated with more severe COVID-19 symptoms. ${ }^{17} \mathrm{~A}$ study conducted in Scotland found that those at higher risk of COVID-19 complications and death were almost 
Table 2 Multinomial logistic regression of intention to vaccinate against COVID-19 among participants in the telephone survey of the Brazilian Longitudinal Study of Aging (ELSI-COVID-19 initiative), 16-29 November 2020

\begin{tabular}{|c|c|c|}
\hline & $\begin{array}{l}\text { Does not intend to } \\
\text { vaccinate (vs does } \\
\text { intend) }\end{array}$ & $\begin{array}{l}\text { Unsure/does not } \\
\text { know (vs does } \\
\text { intend) }\end{array}$ \\
\hline \multirow{2}{*}{$\begin{array}{l}\text { Ages 60-74 } \\
\text { years (vs 50-59 } \\
\text { years) }\end{array}$} & $1.59^{\star *}$ & 0.89 \\
\hline & $1.13,2.21$ & $0.62,1.27$ \\
\hline \multirow[t]{2}{*}{$75+$ years } & $2.46^{\star \star \star}$ & 1.31 \\
\hline & $1.53,3.95$ & $0.81,2.14$ \\
\hline \multirow[t]{2}{*}{ Female } & 1.3 & 0.88 \\
\hline & $0.94,1.79$ & $0.66,1.18$ \\
\hline \multirow{2}{*}{$\begin{array}{l}5-8 \text { years } \\
\text { education (vs } \\
\text { fewer) }\end{array}$} & 0.99 & 0.95 \\
\hline & $0.73,1.34$ & $0.65,1.40$ \\
\hline \multirow{2}{*}{$\begin{array}{l}9+\text { years of } \\
\text { education }\end{array}$} & 1.25 & 0.79 \\
\hline & $0.88,1.78$ & $0.56,1.12$ \\
\hline \multirow{2}{*}{$\begin{array}{l}1-2 \text { chronic } \\
\text { conditions (vs } \\
\text { none) }\end{array}$} & 0.97 & 0.84 \\
\hline & $0.68,1.38$ & $0.55,1.29$ \\
\hline \multirow{2}{*}{$\begin{array}{l}3+\text { chronic } \\
\text { conditions }\end{array}$} & 1.13 & 0.72 \\
\hline & $0.70,1.82$ & $0.40,1.31$ \\
\hline \multirow{2}{*}{$\begin{array}{l}\text { Received } \\
\text { influenza shot } \\
\text { in the past } 12 \\
\text { months }\end{array}$} & $0.63^{\star \star \star}$ & 0.86 \\
\hline & $0.49,0.79$ & $0.55,1.34$ \\
\hline \multirow{2}{*}{$\begin{array}{l}\text { Inconsistent face } \\
\text { mask use }\end{array}$} & $3.41^{\star \star \star}$ & 0.96 \\
\hline & $1.90,6.09$ & $0.55,1.69$ \\
\hline \multirow{2}{*}{$\begin{array}{l}\text { Knows someone } \\
\text { diagnosed with } \\
\text { COVID-19 }\end{array}$} & 1.18 & 0.69 \\
\hline & $0.90,1.54$ & $0.44,1.08$ \\
\hline \multirow{2}{*}{$\begin{array}{l}\text { Source of } \\
\text { COVID-19 } \\
\text { information } \\
\text { is traditional } \\
\text { media (vs official } \\
\text { sources) }\end{array}$} & 0.77 & 0.73 \\
\hline & $0.58,1.02$ & $0.48,1.10$ \\
\hline \multirow{2}{*}{$\begin{array}{l}\text { Social media/ } \\
\text { family/other } \\
\text { sources }\end{array}$} & $1.67^{\star \star}$ & 1.27 \\
\hline & $1.14,2.44$ & $0.73,2.21$ \\
\hline \multirow{2}{*}{$\begin{array}{l}\text { No trusted } \\
\text { source of } \\
\text { information }\end{array}$} & $1.71^{\star \star \star}$ & $1.6^{*}$ \\
\hline & $1.25,2.34$ & $1.03,2.48$ \\
\hline \multirow[t]{2}{*}{ Rural (vs urban) } & 0.91 & 0.77 \\
\hline & $0.71,1.18$ & $0.55,1.09$ \\
\hline \multirow{2}{*}{$\begin{array}{l}\text { North region (vs } \\
\text { Southeast) }\end{array}$} & $0.24^{\star \star \star}$ & 1.72 \\
\hline & $0.11,0.50$ & $0.98,3.02$ \\
\hline \multirow[t]{2}{*}{ Northeast region } & 0.63 & 0.77 \\
\hline & $0.36,1.10$ & $0.50,1.18$ \\
\hline \multirow[t]{2}{*}{ South region } & $0.5^{\star \star}$ & 1.16 \\
\hline & $0.33,0.77$ & $0.76,1.78$ \\
\hline
\end{tabular}

Continued
Table 2 Continued

\begin{tabular}{|c|c|c|}
\hline & $\begin{array}{l}\text { Does not intend to } \\
\text { vaccinate (vs does } \\
\text { intend) }\end{array}$ & $\begin{array}{l}\text { Unsure/does not } \\
\text { know (vs does } \\
\text { intend) }\end{array}$ \\
\hline \multirow[t]{2}{*}{ Midwest region } & 0.79 & 1.56 \\
\hline & $0.37,1.68$ & $0.86,2.82$ \\
\hline \multirow{2}{*}{$\begin{array}{l}\text { Municipal } \\
\text { hospital beds per } \\
\text { capita }\end{array}$} & $0.98^{\star \star}$ & 0.99 \\
\hline & $0.96,0.99$ & $0.98,1.01$ \\
\hline \multirow{2}{*}{$\begin{array}{l}\text { Log municipal } \\
\text { population }\end{array}$} & 1.08 & 0.97 \\
\hline & $0.97,1.21$ & $0.90,1.05$ \\
\hline \multirow{2}{*}{$\begin{array}{l}\text { Municipal } \\
\text { COVID-19 cases, } \\
1000\end{array}$} & 0.99 & $0.99^{*}$ \\
\hline & $0.98,1.01$ & $0.98,1.00$ \\
\hline \multirow{2}{*}{$\begin{array}{l}\text { Municipal } \\
\text { COVID-19 fatality } \\
\text { rate* }^{*}\end{array}$} & $0.89^{*}$ & 0.94 \\
\hline & $0.79,1.00$ & $0.89,1.01$ \\
\hline
\end{tabular}

${ }^{*} p<0.05 ;{ }^{* *} p<0.01 ;{ }^{* \star *} p<0.001$.

Numbers are relative risk ratios and $95 \%$ Cls of survey-weighted multinomial logistic regression. Reference value is those who intend to receive a COVID-19 vaccine when available.

*Total municipal deaths/total municipal cases *100.

two times as likely to accept a COVID-19 vaccine than those without such risk factors. ${ }^{18}$ However, our study did not find any association between health conditions that raise the risk of COVID-19 complications and death and respondents' intention to be vaccinated. This suggests that at least part of the population at risk for such complications has not understood, has not been informed or has chosen to ignore information about their high-risk status. It may also suggest that vaccine intentions are driven by more than one's potential risk for more severe forms of the disease.

Several COVID-19-specific factors were associated with the intention to vaccinate. Potential vaccine refusal was highly correlated with protective measures such as consistent use of face masks when going outside the home. There is evidence that face mask use is associated with lower risk of contracting SARS-CoV-2. ${ }^{19}{ }^{20}$ Moreover, at least some of those who do not use face masks may be subjected to COVID-19-related misinformation regarding the severity of the disease or the effectiveness of cloth face coverings in reducing infection and transmission. ${ }^{21}$ This result implies there is a need for additional promotion of the benefits of face mask wearing in public, from both self-protection and altruistic perspectives. ${ }^{22}$ Neither a previous COVID-19 diagnosis nor knowledge of an individual who had contracted the disease was significantly associated with intention to vaccinate against the disease, similar to results found in previous studies. ${ }^{7}$

A strong and consistent predictor of vaccine intention was an individuals' most trusted source of information about COVID-19. Official sources (Ministry of Health or state or local government), followed by the traditional press, were the most prevalent among all groups and was associated with greater 

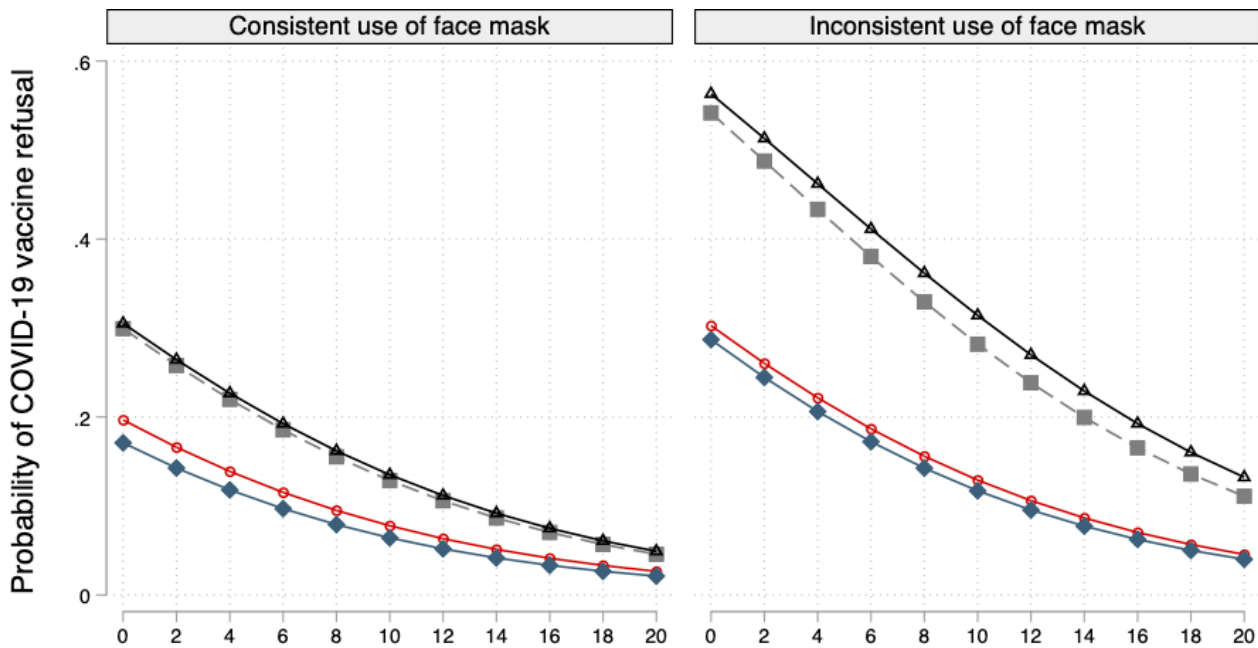

Cumulative municipal COVID-19 fatality rate (\%)

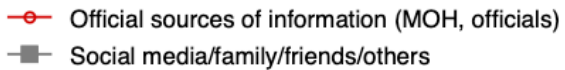

$\checkmark$ Traditional media sources

$\triangle$ Does not trust any information source

Figure 2 Predicted probability of intention to refuse a COVID-19 vaccine, by most trusted source of information, consistency of face mask use, and municipal COVID-19 fatality ratio among participants in the telephone survey of the Brazilian Longitudinal Study of Aging (ELSI-COVID-19 initiative), 16-29 November 2020.

intention to vaccinate. Still, a sizeable proportion of individuals in each region (ranging from $29 \%$ in the Northeast to $52 \%$ in the North) who most trusted official sources nevertheless had negative vaccine intentions. Given the novelty of COVID-19 and the preliminary nature of early announcements of vaccine efficacy, some level of uncertainty or doubt is probably warranted. Examination of open-ended responses as to why individuals said they would not receive a vaccine indicated 'fear' or 'lack of confidence' in safety or efficacy as the most common explanations, closely followed by doubt about the integrity of the vaccine manufacturer-especially if not produced in Brazil, and antivaccine statements such as, 'vaccines kill' (data not shown). For these reasons, public health officials must demonstrate more effectively the safety of the vaccine and work to counteract antivaccine messaging through official channels as well as social media and other informal sources that are more heavily relied on among those with negative or uncertain vaccine intentions. ${ }^{1623-25}$

Contextual factors were more consistently associated with vaccine refusal than with vaccine uncertainty. The SARSCoV-2 epidemic has progressed heterogeneously in different regions of the country. The Southeast, Northeast and North

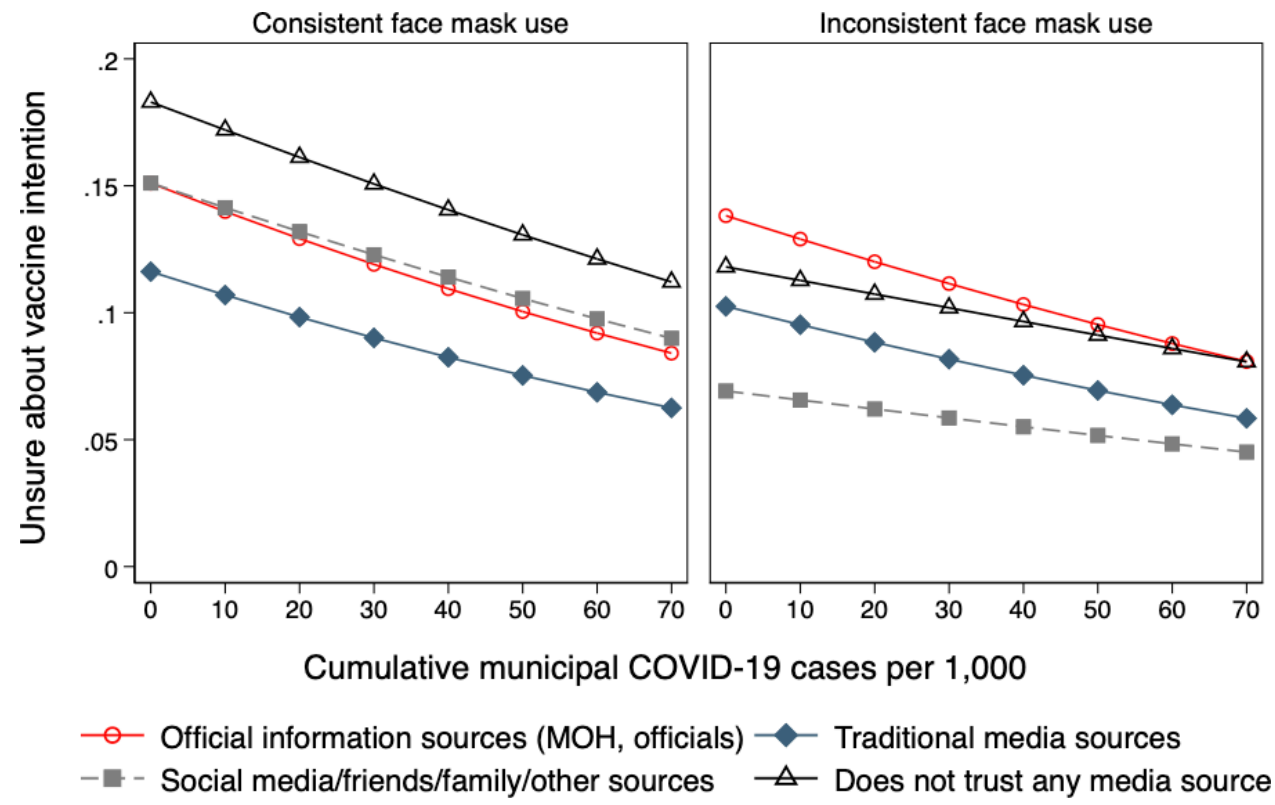

Figure 3 Predicted probability of being unsure about one's intention to receive a COVID-19 vaccine, by most trusted source of COVID-19-related information, consistency of face mask use, and municipal COVID-19 cases among participants in the telephone survey of the Brazilian Longitudinal Study of Aging (ELSI-COVID-19 initiative), 16-29 November 2020. 
regions first presented the initial cases, while in the South and Midwest regions, cases increased later. ${ }^{26}$ The highest proportion of vaccine refusal was observed in the Southeast (23.8\%) and the lowest in the North region (7.2). This is in spite of the fact that, at the time of the interview, the Southeast and South regions (most populous) had the highest absolute numbers of reported cases and deaths (not rates) ${ }^{26}$ Analysis of municipal-level (rather than regional-level) COVID-19 cases and fatality rates showed that the higher the municipal rates, the lower the likelihood of vaccine uncertainty and refusal, respectively. This suggests that the severity of the epidemic in one's own municipality (as opposed to trends at the regional level, which would mask municipal-level heterogeneity) may be an important contributor to vaccine intentions.

Brazil has one of the most extensive immunisation programmes in the world. Since 1999, influenza vaccines are provided free-of-charge to all adults aged 60 years or more. ${ }^{27}$ While influenza immunisation coverage has remained close to the $75 \%$ target proposed by the WHO, only $65 \%$ of participants reported receiving a influenza shot in past year (preCOVID-19). Moreover, previous receipt of a influenza shot was negatively associated with vaccine refusal (OR 0.63; $95 \%$ CI 0.49 to 0.79 ). There may, therefore, be a contingent of older adults who have become less receptive even to betterknown vaccines such as those for influenza and this attitude or experience may affect their acceptance of a COVID-19 vaccine.

The importance of the Brazilian health system and its unique community-based primary healthcare model, the FHS, should also not be underestimated. Older adults affiliated with the FHS were found to be $36 \%$ more likely than those not affiliated to be vaccinated against influenza. ${ }^{27}$ The reach of the FHS (covering about $61 \%$ of the Brazilian population) and its nearly 260000 community health agents who make household visits on a regular basis provides an opportunity to involve primary care units in vaccine delivery as well as in communications efforts. The use of population-based registers of households covered by the FHS may provide an additional tool to identify individuals who should be prioritised to receive a COVID-19 vaccine and those who have not been vaccinated. ${ }^{28}$ Nevertheless, neither household enrollment in the FHS nor municipal-level FHS coverage rates were associated with the intention to vaccinate. This may be because, at least up until the time of the interview, these resources were not actively incorporated into a national antiCOVID-19 strategy. ${ }^{29}$

The major strength of this study is its large population base, with over 6500 interviews carried out among older adult residents prioritised for COVID-19 vaccination in 70 municipalities in all five major Brazilian regions. Another advantage is its inclusion in a well-defined populationbased cohort, allowing for examination of an array of factors obtained from pre-COVID in-person interviews as well as via the post-COVID telephone surveys. Furthermore, this study goes beyond a dichotomy of vaccine acceptance/refusal to include the category of vaccine uncertainty, which has not been as well explored in the context of COVID-19. Unfortunately, there were few factors identified that were significantly associated with vaccine uncertainty, as compared with vaccine refusal. This suggests the importance of continuing to separate vaccine refusal from uncertainty in any study. It also suggests the need for further investigation into the determinants of vaccine uncertainty in general and to explicitly test the assumption that it may be easier to sway someone who is uncertain to accept a vaccine than someone who intends to refuse it.

The limitations of the study are those inherent to crosssectional telephone surveys, including self-report and recall bias, respondents not answering calls or refusing to provide information via this means and incorrect or non-existent phone numbers. ${ }^{13}$ To compensate for nonresponse, we used weights specifically derived for respondents for each wave of the telephone interview. Using these weights and sample parameters, the distribution of sociodemographic characteristics of study participants was similar to that of the Brazilian population in the same age group (see online supplemental appendix). However, we cannot rule out the possibility of bias due to unmeasured factors that could affect phone availability or response. Finally, it is important to note that positive vaccine intentions may not automatically translate into receipt of a vaccine as such decisions are complex and may be driven by factors that change over time. ${ }^{7}$

\section{CONCLUSION}

The task ahead of the Brazilian government is to deliver vaccines as quickly as possible, with a priority for vulnerable populations, such as the elderly and those with specific health conditions. This task will require clear, unambiguous and targeted messaging to convince those who are unsure about the importance and urgency of receiving a COVID-19 vaccine. A far greater challenge will likely be reaching and changing the minds of those nearly 9 million older Brazilians who have said they will not take a COVID-19 vaccine. This task that will require intensive, evidence-based social marketing and other approaches carried out on a massive scale. It will require mobilisation of the nation's health system as well as political leaders and civil society to explain consistently and clearly the benefits (and risks) of each vaccine and to counteract unfounded claims regarding such important protective measures.

\section{Author affiliations \\ ${ }^{1}$ Department of Health Policy and Management, University of California Los Angeles Jonathan and Karin Fielding School of Public Health, Los Angeles, California, USA ${ }^{2}$ Department of Community Health Sciences, University of California Los Angeles Jonathan and Karin Fielding School of Public Health, Los Angeles, California, USA ${ }^{3}$ Programa de Pós Graduação em Saúde Pública, Universidade Federal de Minas Gerais, Belo Horizonte, Brazil \\ ${ }^{4}$ Núcleo de Estudos em Saúde Pública e Envelhecimento, Fundacao Oswaldo Cruz Instituto Rene Rachou, Belo Horizonte, Brazil}

Contributors JM verified the data, performed data analyses, wrote the manuscript, interpreted results and is the garantor. BVS conducted the literature review, performed data visualizations and contributed to the manuscript writing. JVMM 
verified the data and performed data analyses. MFL-C conceived of the idea for the paper, contributed to the manuscript writing, interpreted results and directed the study design and data collection. All authors reviewed and approved the final manuscript.

Funding The baseline and second wave of the ELSI-Brasil aging cohort study was funded by the Brazilian Ministry of Health: Departamento de Ciência e Tecnologia da Secretaria de Ciência e Tecnologia e Insumos Estratégicos-DECIT/SCTI) (processos numbers 404965/2012-1 e 28/2017) and Coordenação da Saúde da Pessoa Idosa da Secretaria de Atenção à Saúde -COSAPI/DAPES/SAS (TED: 20836, 22566, 23700 and 77/2019). The ELSI-COVID-19 initiative is funded by DECIT/SCTI and by the National Council for Scientific and Technological Development (CNPq: processo 403473/2020-9). MFLC is supported by a CNPq 1 A research productivity award. The funding source had no role in study design, analysis or interpretation.

Competing interests None declared.

Patient consent for publication Not applicable.

Ethics approval All participants provided written informed consent. The ELSIBrazil household-based cohort study and the ELSI-COVID-19 telephone survey were approved by the ethics board of the 0swal-do Cruz Foundation in Minas Gerais (CAAE: 34649814·3.0000-5091 and CAAE: 33492820·3·0000-5091, respectively).

Provenance and peer review Not commissioned; externally peer reviewed.

Data availability statement Data are available in a public, open access repository. Data are available upon reasonable request. The $2015-16$ baseline data and documentation are available on ELSI-Brazil project website (elsi.cpqrr.fiocruz). The 2019-20 ELSI second wave data and the ELSI-COVID-19 surveys are housed at the Fundação Oswaldo Cruz, Minas Gerais, Brazil. Following completion of data collection, cleaning, construction of weights, and creation of the users' guide, which is estimated to occur in mid-2021, all data will be publicly available on the project website.

Supplemental material This content has been supplied by the author(s). It has not been vetted by BMJ Publishing Group Limited (BMJ) and may not have been peer-reviewed. Any opinions or recommendations discussed are solely those of the author(s) and are not endorsed by BMJ. BMJ disclaims all liability and responsibility arising from any reliance placed on the content. Where the content includes any translated material, BMJ does not warrant the accuracy and reliability of the translations (including but not limited to local regulations, clinical guidelines, terminology, drug names and drug dosages), and is not responsible for any error and/or omissions arising from translation and adaptation or otherwise.

Open access This is an open access article distributed in accordance with the Creative Commons Attribution Non Commercial (CC BY-NC 4.0) license, which permits others to distribute, remix, adapt, build upon this work non-commercially, and license their derivative works on different terms, provided the original work is properly cited, appropriate credit is given, any changes made indicated, and the use is non-commercial. See: http://creativecommons.org/licenses/by-nc/4.0/.

\section{ORCID iDs}

James Macinko http://orcid.org/0000-0001-8055-5441

M Fernanda Lima-Costa http://orcid.org/0000-0002-3474-2980

\section{REFERENCES}

1 Ministério da Saúde. Boletim Epidemiológico 10. Situação epidemiológica dA COVID-19: doença pelo coronavírus 2020, 2020. Available: https://covid.saude.gov.br/

2 Johns Hopkins University. COVID-19 Dashboard, 2020. Available: https://coronavirus.jhu.edu/map.htm

3 Shahid Z, Kalayanamitra R, McClafferty B, et al. COVID-19 and older adults: what we know. J Am Geriatr Soc 2020;68:926-9.

4 Instituto Brasileiro de Geografia e Estatística (IBGE). Sistema IBGE de Recuperação Automática - SIDRA, 2021. Available: https://sidra. ibge.gov.br/home/pms/brasil

5 Macinko J, Seixas BV, Woolley NO, et al. Prevalence and characteristics of Brazilians aged 50 and over that received a doctor's diagnosis of COVID-19: the ELSI-COVID-19 initiative. Cad Saude Publica 2020;36Suppl 3:e00190320.
6 Evans D, Over M. The economic impact of COVID-19 in low- and middle-income countries. center for global development, 2021. Available: https://www.cgdev.org/blog/economic-impact-covid-19low-and-middle-income-countries

7 Lazarus JV, Ratzan SC, Palayew A, et al. A global survey of potential acceptance of a COVID-19 vaccine. Nat Med 2021;27:225-8.

8 Larson HJ, Jarrett C, Eckersberger E, et al. Understanding vaccine hesitancy around vaccines and vaccination from a global perspective: a systematic review of published literature, 2007-2012. Vaccine 2014;32:2150-9.

9 Gallup. Wellcome global monitor 2018, 2019Gallup. Available: https://wellcome.org/sites/default/files/wellcome-global-monitor2018.pdf [Accessed October 1, 2021].

10 Fujita DM, Salvador FS, Nali LHdaS, et al. Decreasing vaccine coverage rates lead to increased vulnerability to the importation of vaccine-preventable diseases in Brazil. J Travel Med 2018;25.

11 Césare N, Mota TF, Lopes FFL, et al. Longitudinal profiling of the vaccination coverage in Brazil reveals a recent change in the patterns hallmarked by differential reduction across regions. Int $J$ Infect Dis 2020;98:275-80.

12 [Dataset] Lima-Costa MF. The Brazilian longitudinal study of aging (ELSI-Brazil), 20200swaldo Cruz Foundation Rene Rachou Research Institute. Available: http://elsi.cpqrr.fiocruz.br/en/ [Accessed November 10, 2020].

13 Lima-Costa MF, Macinko J, de AFB, et al. ELSI-COVID-19: methodology of the telephone survey on coronavirus in the Brazilian longitudinal study of aging. Cad Saude Publica Oct 12;36Suppl 3:e00183120.

14 [Dataset] Cota W. Monitoring the number of COVID-19 cases and deaths in Brazil at municipal and federative unit level 2020.

15 Ministério da Saúde. Plano preliminar de vacinação Contra a Covid-19 prevê quatro fases, 2021. Available: https://www.gov.br/ saude/pt-br/assuntos/noticias/vacinacao-contra-a-covid-19-serafeita-em-quatro-fases

16 Lin C, Tu P, Beitsch LM. Confidence and receptivity for COVID-19 vaccines: a rapid systematic review. Vaccines 2021;9:16.

17 CDC, COVID-19 and Your Health. Centers for disease control and prevention, 2020. Available: https://www.cdc.gov/coronavirus/2019ncov/need-extra-precautions/evidence-table.html

18 Williams L, Flowers P, McLeod J, et al. Social patterning and stability of intention to accept a COVID-19 vaccine in Scotland: will those most at risk accept a vaccine? Vaccines 2021;9:17.

19 Howard J, Huang A, Li Z, et al. Face masks against COVID-19: an evidence review 2020

20 Greenhalgh T, Schmid MB, Czypionka T, et al. Face masks for the public during the covid-19 crisis. BMJ 2020;369:m1435.

21 Hornik R, Kikut A, Jesch E, et al. Association of COVID-19 misinformation with face mask wearing and social distancing in a nationally representative US sample. Health Commun 2021;36:6-14.

22 Cheng KK, Lam TH, Leung CC. Wearing face masks in the community during the COVID-19 pandemic: altruism and solidarity. Lancet 2020. doi:10.1016/S0140-6736(20)30918-1. [Epub ahead of print: 16 Apr 2020]

23 Laine C, Cotton D, Moyer DV. COVID-19 vaccine: what physicians need to know. Ann Intern Med 2020;173:830

24 Romer D, Jamieson KH. Conspiracy theories as barriers to controlling the spread of COVID-19 in the U.S. Soc Sci Med 2020;263:113356.

25 Généreux M, David MD, O'Sullivan T, et al. Communication strategies and media discourses in the age of COVID-19: an urgent need for action. Health Promot Int 2021:36:1178-85.

26 Saúde Mda. Boletim Epidemiológico 41. Situação epidemiológica dA COVID-19: doença pelo coronavírus 2020, 2020. Available: https:// covid.saude.gov.br/

27 Sato APS, Antunes JLF, Lima-Costa MFF, et al. Influenza vaccine uptake among older adults in Brazil: socioeconomic equality and the role of preventive policies and public services. $J$ Infect Public Health 2020;13:211-5

28 Danchin M, Biezen R, Manski-Nankervis J-A, et al. Preparing the public for COVID-19 vaccines: how can general practitioners build vaccine confidence and optimise uptake for themselves and their patients? Aust J Gen Pract 2020;49:625-9.

29 Daumas RP, Silva GAE, Tasca R, et al. The role of primary care in the Brazilian healthcare system: limits and possibilities for fighting COVID-19. Cad Saude Publica 2020;36:e00104120. 